\title{
Role of Nuclear Power in the Future: Cost and Public Acceptance Changjian Wang ${ }^{1, a}$ \\ ${ }^{1}$ Guangzhou Institute of Geography Guangdong Open Laboratory of Geospatial Information Technology and Application, Guangzhou 510070
}

awwwangcj@126.com

Keywords: Nuclear power, Cost, Public acceptance

\begin{abstract}
The Fukushima accident pushed nuclear energy into dark criticism. Five years after, Japan is still faltering in its response to phase out nuclear. Global generating electricity from nuclear has decreased. Unfortunately, capital costs for renewables continue to fall, but costs of nuclear power keep rising. In addition, nuclear waste storage and spent fuel management problems are still unsolved. What's the nuclear power future? It has been plagued by the high cost of construction for a long time and the uncertain public acceptance after the Fukushima, as well as other strong competitors from renewables and fossil shale-gas in the near future.
\end{abstract}

\section{Introduction}

Access to affordable and reliable energy source has been a cornerstone of the world's increasing prosperity and economic growth since the industrial revolution. But, providing stable and sustainable energy service to meet the increasing needs of a growing population with rising living standards is still a big challenge worldwide. Besides, there are still billions of people suffering energy poverty, who still lack of basic and modern energy services. Volatile energy prices, concerns about the security of fuel supplies and electricity-generation gaps, are coinciding to strengthen the case for developing relatively cheap energy to drive economic growth. The threat of the global climate crisis which perhaps is one of the most forceful policy drivers, justify the development of carbon-free energy - nuclear power. Consequently, nuclear energy was receiving new attention after the Chernobyl.

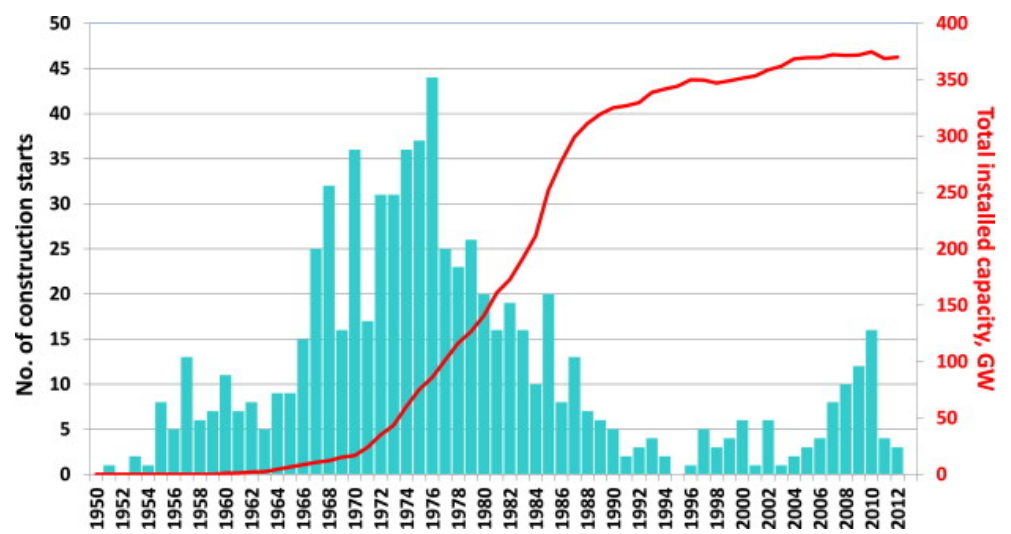

Fig. 1 Number of construction starts globally and total installed generating capacity [1].

The impressive expansion of nuclear construction started in the late 1960s, but slowed down after the Three Mile Island in 1979 and the Chernobyl in 1986 (see Fig. 1). The total installed nuclear capacity has stagnated since the early 1990 [2]. After more than 60 years of development, 
nuclear energy has made great contribution to social economic development, once with high hopes for stemming the tide of climate change and ending the era of fossil fuel.

\section{Nuclear Power before Fukushima}

Addressing the constantly power outage troubles or the rising electricity prices, some developing countries are committed to nuclear power, such as Vietnam and Nigeria[3]. Considering the high growth rates in demand for electricity and energy security concerns, five North African countries had plans to develop nuclear power, where nuclear power could supply up to $9 \%-15 \%$ of all electricity consumption by 2030. China, the world's largest primary energy consumer and carbon emissions emitter after decades of rapid economic growth [4, 5], believes that nuclear might help curb the demands for fossil fuels and reduce carbon dioxide emissions per unit of GDP by 40 to $45 \%$ in 2020 relative to the 2005 levels [6, 7]. China's nuclear capacity is projected to come to at least $58 \mathrm{GW}$ including the new and approved units by 2020, 200GW by 2030, and 400GW by 2050 [8]. Another emerging economy, India, expects to have $15 \mathrm{GW}$ nuclear capacity by 2020 in which electricity supply from nuclear power will be $25 \%$ by the middle of the century [9]. Russia is moving steadily forward with $50 \%$ nuclear power increased output by 2020 . Nuclear goods and services exports will constitute a major Russian energy policies and economic objectives. Nuclear energy was also introduced as part of Australia's future energy mix if it would help tackle climate change and other energy alternatives would not provide low-cost electricity [10]. Obviously, the locus of the nuclear markets was moving from the "West" to "East”, with China, India, the Republic of Korea and Russia emerging as the mainly driving forces for nuclear recent renaissance throughout the world [11, 12], especially the emerging economies and developing countries who were in great need of additional power supply to drive its economic growth.

\section{Nuclear Power after Fukushima}

While the world was experiencing a nuclear renaissance, an earthquake followed by tsunami attacked the Fukushima nuclear power plants. The Fukushima Daiichi nuclear accident of Japan in March 2011 pushed this energy star into dark criticism. A heated discussion about the future of nuclear energy has been never stopped. The installed nuclear generating capacity was 375.5 GWe on 10 March 2011, accounted for 13.5\% of global electricity supply [1]. After the Fukushima, there were 437 nuclear power reactors in operation by the end of 2012 in the world, with a combined installed nuclear generating capacity of 373.1 GWe, accounted for $11.3 \%$ of global electricity supply. Then, there were 435 reactors in operation with a combined installed nuclear generating capacity of 372.8 GWe by the end of 2013.

Japan's Post-Fukushima Challenge. Japanese government has presented three scenarios of nuclear reduction (i.e. zero nuclear, $15 \%$ nuclear, and $20-25 \%$ nuclear) in post-Fukushima. The accident forced the Japanese Government to suspend all nuclear plants under construction. Fukushima 1-4 units were to be decommissioned, and the remaining 50 plants were shut down successively. In July 2012, the Ohii No. 3 and 4 units were restarted to avoid the possible blackouts during the peak demands season in the Kansai region [13].

Tokyo Electric Power Company (TEPCO)'s liability for the losses caused by the Fukushima accident is speculated to reach several trillion. The direct consequence shows that Japan is paying billions of dollars for additional fossil fuels (oil and natural gas) for its power generation to make up for the lost nuclear power $[13,14]$. Electric Power Company, meanwhile, is applying to raise electricity prices in order to offset the soaring fossil fuel imports. The high electricity costs may 
likely disturb the citizen's life and industrial activities in Japan [13]. Peak hour electricity consumption was reduced by $18 \%$ in the Tokyo region in summer 2011, consequently, factories tended to shift production times, while commercial businesses tended to illumination and air-conditioning reduction. Denuclearization's indirect consequences, that is, reduction of affordable electricity access, would exacerbate numerous social problems including public health, education, etc.

Countries Phase Out Nuclear Power Plants. After the Fukushima, four countries (Germany, Switzerland, Italy and Belgium) have decided to phase out nuclear power programs or not to re-introduce nuclear power [12]. Eight units in Germany were forced to permanently shut down and stop electricity generation by political decisions in 2011, and the share of electricity production from nuclear performed a sharply decline from $23 \%$ in 2010 to $17.79 \%$ in $2011,16.10 \%$ in 2012, then to $15.45 \%$ in 2013. In addition, the remaining nine reactors in Germany were pledged to phase out by 2022, with an ambitious strategy to fully replace nuclear power with renewable energy. Belgium decided to phase-out seven nuclear plants during 2015 to 2025, which produced more than half of the national domestic electricity. Peoples in these countries participated in the overwhelming anti-nuclear movements, who were reluctant to see their own country's electricity generated by nuclear energy. According to a nation-wide survey in Italy before the Fukushima, a lot of Italian households dislike nuclear energy, while show strong preference for wind and solar energy. In some sense, Japan's Fukushima accident helped stimulate the opposition attitudes. Meanwhile, policy makers had to reconsider the country's nuclear energy policy in the case of the political interests or even the presidential election. In order to make up the shortfall, Chancellor Angela Merkel promised that Germany would double the proportion of electricity generated from renewable energy from $17 \%$ to $35 \%$ by 2020 , expecting to become a world leader in wind and solar power, especially increasing the share of wind power sector, and about $2 \mathrm{GW}$ of wind power is newly added in Germany in 2011. Belgium and Italy also have decided to promote renewables.

\section{Nuclear Power in the Future}

Nuclear power is a low-carbon power source. Nuclear power was always seen as a powerful tool with high hopes in mitigating Greenhouse gas. According to a report after the Fukushima, coal power would benefit if the renewable energy can't meet the demand, a $370 \mathrm{Mt}$ increase in carbon dioxide emissions from Germany generators would attribute to the burning of fossil fuel. The phase-out of nuclear would increase Greenhouse gas emissions by $2 \%$ globally and $7 \%$ for Annex I countries under the Kyoto Protocol [15].

Costs. What's the nuclear power future? But it is neither cheap nor safe. Long time period required for construction means an extremely high capital costs and long return on investments time, indicating that capital cost is a critical parameter for evaluating the viability of nuclear power [16]. Compared with other energy technologies, there are no positive scale economies in the nuclear power construction, furthermore, specific investment costs have become ever more expensive [2]. South Korea can beat France, USA and Japan in the UAE nuclear bid, the most important reason is its APR-1400 lowest construction cost.

The projected overnight capital costs of Gen III/III+ nuclear power plants increased significantly during the past decade. Construction costs for new generation III+ nuclear power plants were estimated at $\$ 1000 / \mathrm{kW}$ by 2002 , then soared to $\$ 5000 / \mathrm{kW}$ for $2007 / 2008$ [2]. Even the low estimate of construction costs of $\$ 5335 / \mathrm{kW}$ in 2010 are more expensive [2], compared to $\$ 2800 / \mathrm{kW}$ and $\$ 1000 / \mathrm{kW}$ for coal and natural gas [16]. In contrast, costs of photovoltaic module and wind turbines in U.S. have fallen by about $10 \%$ and roughly $5 \%$ per year over the past 30 years, respectively [17]. 
Capital costs for renewables (i.e. wind and solar) continue to fall, but the costs of nuclear power keep rising in Europe [18]. Contractual price for the European Pressurized Reactor in 2004 was $\$ 3000 / \mathrm{kW}$, then to $\$ 5000 / \mathrm{kW}$ due to 4 years behind construction schedule [2]. Capital costs of building nuclear power plants VVER have increased considerably from $\$ 1000 / \mathrm{kW}$ in 2000 to exceed $\$ 3000 / \mathrm{kW}$ in Russia, besides, operating \& maintaining costs and nuclear electricity costs have also increased [19]. What is more serious is that EU Member States with a large share of nuclear power often have high electricity price levels for both households and industry customers, revealed by the German Institute for Applied Ecology in 2008. Now, the cost competitiveness of nuclear power in liberalized electricity markets is not at all clear [16].

In addition to the increasing construction costs, nuclear waste storage and spent fuel management problems are still unsolved. The license application for Yucca Mountain to handle nuclear waste has been plagued by political opposition, fiscal constraints, technical problems, and legislation challenges until now. The spent nuclear fuel storage costs are almost 10 times higher than carbon storage costs per electricity produced in Lithuania. And those costs are not just high if a country opts to give up nuclear power, just like Switzerland. Furthermore, the worldwide undergoing safety \& security reviews and stress tests will add additional costs to already nuclear power stations in place and new plants even more. Onshore wind, solar PV and hydro have much lower fixed operating \& maintaining costs and zero variable costs [2]. Under such a circumstance, other renewable energy sources are already or becoming more competitive, if the higher life-cycle costs of nuclear power are not seriously concerned. All these key challenges will make nuclear power less competitive, compared to other forms of electricity production.

Strong Competitor. Moreover, the U.S. shale-gas revolution means that nuclear power is faced with another strong competitor-the low cost natural gas for power generation. U.S. natural gas wellhead prices fell sharply in 2008 [16]. The electricity production costs of gas in U.S. also fell dramatically after 2008 (see Fig. 2). Total generating electricity from Gas-fired power plants has increased from 25\% in 2011 to 30\% in 2012. During the same period, nuclear power plants provided $19.25 \%$ of U.S. total generating electricity in 2011, 19.44\% in 2013. Exelon, one of the largest U.S. nuclear companies, said that they would not break ground on a new nuclear plant only until natural gas price was more than double the level of 2010 and carbon emissions cost \$25/ton [16]. Actually, the average annual wellhead prices for natural gas projected by EIA will remain below \$5.1 per million BTU (2010 dollars) through 2023, the shale-gas revolution will keep contributing to a new era of cheap natural gas in the U.S. in the near medium-term [20].

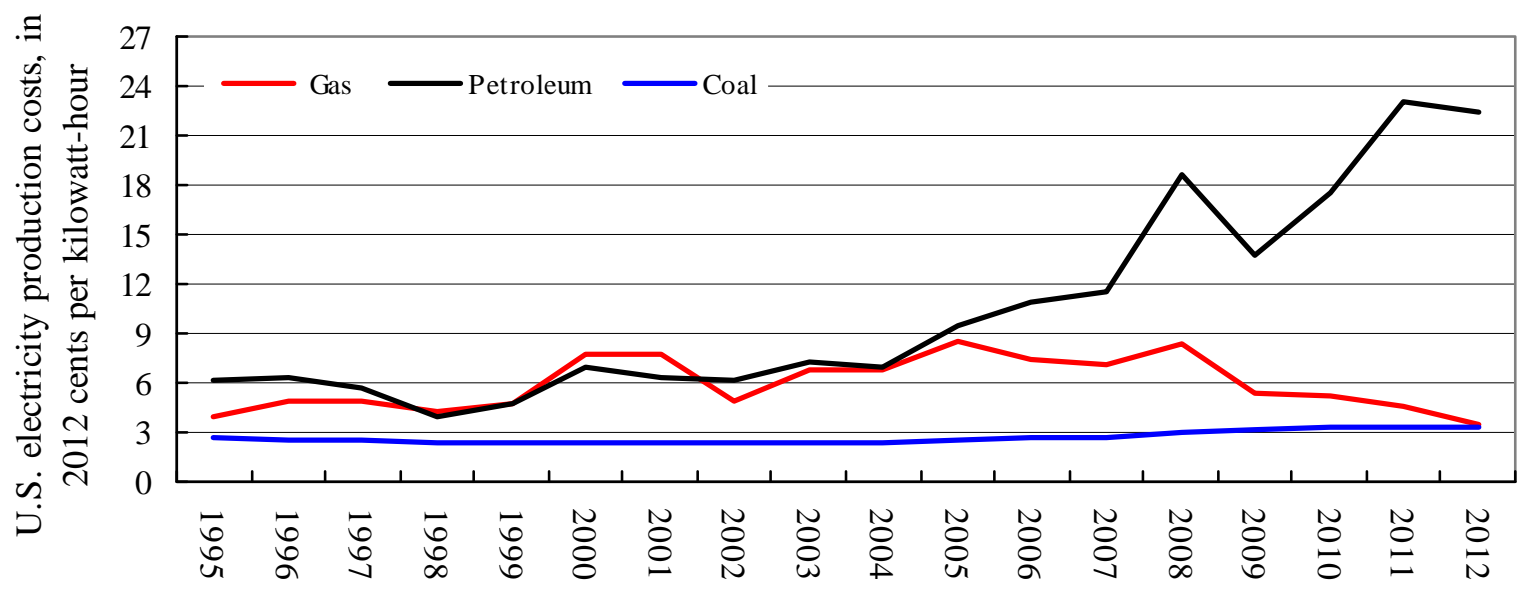

Fig. 2 U.S. electricity production costs in 2012 cents per kilowatt-hour from 1995 to 2012. 
Acceptance. The Fukushima posed negative impacts on the acceptance of nuclear. For the sake of none loopholes in the nuclear power management, we must remember the Fukushima is not natural disaster, but the regulatory failures. Nuclear accidents and higher risk perceptions make the public acceptance of nuclear power become another crucial factor for establishment of a new nuclear energy program [11]. Social science and social behaviors are also involved in the civilian use of nuclear power. Public attitudes towards nuclear power have been deeply surveyed on the global and local perspectives. Knowledge, trust, risk, and benefit are the most important factors on public acceptance of nuclear power. Changes in perceived benefits after the Fukushima accident strongly influenced the public acceptance of nuclear power in Switzerland. A majority of respondents (40\%) were not willing to accept nuclear power due to safety concerns and distrust [10]. Opposition to nuclear power was also strong in Turkey, and opponents were found to be pessimistic about the future of nuclear.

In order to re-build public acceptance of nuclear power, lessons learnt from Fukushima and yet to be learnt have to be introduced, re-learned and re-emphasized in a transparent, effective, and authoritative way. Public involvement and perceptions, knowledge and risk perceptions, credible and transparent regulations should be emphasized in the ongoing and future nuclear portfolio.

\section{Conclusion}

We are in favor of nuclear power. The advantage of being able to produce energy for 24 hours, guaranteeing base-load security for the electricity supply, and essentially free of greenhouse gas emissions will make nuclear more competitive in the future. Nuclear energy will be a reliable option to supply the world's increasing energy needs for a more sustainable future. But the increasing costs, public acceptance, nuclear safety culture, and nuclear waste storage and spent fuel management are all challenges lying ahead. If not, nuclear power will be the last best option after other renewables (i.e. wind energy and solar PV), perhaps after fossil fuels (low cost shale-gas and even clean coal with CCS).

\section{Acknowledgement}

In this paper, the research was sponsored by the National Nature Science Foundation of China (No. 41501144).

\section{References}

[1] H. H. Rogner, World outlook for nuclear power. Energ. Strategy Rev. 1(4) (2013) 291-295.

[2] L. Mez, Nuclear energy-Any solution for sustainability and climate protection? Energ. Policy. 48 (2012) 56-63.

[3] C. Wang, Q. Wang, F. Wang. Is Vietnam Ready for Nuclear Power? Environ. Sci. Technol. 46(10) (2012) 5269-5270.

[4] C. Wang F. Wang, H. Zhang, Y. Ye, Q. Wu, China's Carbon Trading Scheme is a Priority. Environ. Sci. Technol. 48(23) (2014) 13559-13559.

[5] C. Wang, F. Wang, H. Zhang, Y. Ye, Q. Wu, Y. Su, Carbon emissions decomposition and environmental mitigation policy recommendations for sustainable development in Shandong province. Sustainability. 6(11) (2014) 8164-8179.

[6] C. Wang, X. Zhang, F. Wang, J. Lei, L. Zhang, Decomposition of energy-related carbon 
emissions in Xinjiang and relative mitigation policy recommendations. Front Earth Sci. 9(1) (2015) 65-76.

[7] C. Wang, F. Wang, Structural decomposition analysis of carbon emissions and policy recommendations for energy sustainability in Xinjiang. Sustainability. 7(6) (2015) 7548-7567.

[8] X. J. Yang, D. Zhang, M. Xu, J. Li, China's Nuclear Power Goals Surge Ahead. Science. 340(6129) (2013) 142.

[9] R. B. Grover, Green growth and role of nuclear power: A perspective from India. Energ. Strategy Rev. 1(4) (2013) 255-260.

[10]D. K. Bird, K. Haynes, R. van den Honert, J. McAneney, W. Poortinga. Nuclear power in Australia: A comparative analysis of public opinion regarding climate change and the Fukushima disaster. Energ. Policy. 65(0) (2014) 644-653.

[11]S. Thomas, What will the Fukushima disaster change? Energ. Policy. 45 (2012) 12-7.

[12]L. E. Echavarri, The future of nuclear power. Energ. Strategy Rev. 1(4) (2013) 221-222.

[13]N. Tanaka, Big Bang in Japan's energy policy. Energ. Strategy Rev. 1(4) (2013) 243-246.

[14]V. Vivoda, Japan's energy security predicament post-Fukushima. Energ. Policy. 46 (2012) 135-143.

[15]V. Duscha, K. Schumacher, J. Schleich, P. Buisson, Costs of meeting international climate targets without nuclear power. Climate Policy. 14(3) (2013) 327-352.

[16]L. W. Davis, Prospects for Nuclear Power. J. Econ. Perspect. 26(1) (2012) 49-66.

[17]J. E. Trancik, Back the renewables boom. Nature. 507 (2014) 300-302.

[18]S. van Renssen, The nuclear paradox. Nature Clim Change. 3(9) (2013) 779-780.

[19]E. O. Adamov, A. V. Dzhalavyan, A. V. Lopatkin, N. A. Molokanov, E. V. Muravyov, V. V. Orlov, et al. Conceptual framework of a strategy for the development of nuclear power in Russia to 2100. Atomic Energ. 112(6) (2012) 391-403.

[20]C. Wang, F. Wang, H. Du, X. Zhan, Is China really ready for shale gas revolution —Re-evaluating shale gas challenges. Environ. Sci. Policy. 39(0) (2014) 49-55. 